\title{
2019-nCoV: a worldwide concern and facts
}

\author{
Rajani Sharma $^{1}$ (i) Gargi Akhoury ${ }^{2}$
}

Received: 5 May 2020/Accepted: 24 September 2020/Published online: 16 October 2020

(C) Indian Virological Society 2020

\begin{abstract}
A recent outbreak of endemic disease speeded by a virus whose genome is similar to that of SARS and MERS which outbreak in 2002 and 2012 respectively. All these are zoonotic infection which means these has transmitted from animal to human. Another similarity amongst these infections is that bat is supposed to be primary reservoir for these viruses. 2019-nCoV was reported by WHO on 31 December 2020 which is spreading with alarming rate. WHO has considered this infection as pandemic which means that if the infection is misled then it will spread fear and will cause unnecessary suffering and death. The onset of infection shows general symptoms of flu which later on develops to pneumonia. The main challenge of the infection is that a defined vaccine or medicine is still under trial. Treatment is done on the basis of symptoms and recovery is dependent on the immune response of the patients. This review article is based on meta-analysis of the data where the relation between reproduction number $\left(\mathrm{R}_{0}\right)$ and infection rate is well depicted. Most of the countries has $\mathrm{R}_{0}>1$ which says the infection is epidemic. Symptoms and possible treatment till date is well defined in this paper. Though the COVID-19 virus has changed its strain and came up with asymptomatic infection which is more challenging. Here we
\end{abstract}

Rajani Sharma

rsharma@rnc.amity.edu; rajani.bharatiya@gmail.com

Gargi Akhoury

gakhoury@rnc.amity.edu

1 Amity Institute of Biotechnology, Amity University Jharkhand, Niwaranpur, Ranchi 834002, India

2 Amity School of Engineering and Technology, Amity University Jharkhand, Niwaranpur, Ranchi 834002, India present all the relevant information and facts about novel corona virus.

Keywords 2019-nCoV · Zoonotic disease - Epidemic · Pandemic $\cdot$ Reproduction number

\section{Introduction}

These days a novel coronavirus which belongs to Severe Acute Respiratory Syndrome (SARS) and Middle East respiratory syndrome (MERS) family has become a pandemic worldwide and named as 2019-nCoV. Its spread rate is alarming and has thus been classified as a social as well as an economic concern. Lack of knowledge is creating panic and difficulty to take steps against its infectious rate. Corona has emerged as epidemical disease. It has originated from Wuhan, Hubei Province, in the month of December through direct exposure to the seafood and animal market $[33,2]$ and spreading through contact at alarming rate.

It spread through contact in four different stages. In stage-1, there is transmission of disease from animal to human or it can invade nearby area by migration of infected people. As in China human got the infection from animals and because of their migration it invaded to other counties too. In stage-2, infection is transmitted through contact from one person to another which is known as local transmission. Till stage- 2 it is easy to control the infection but as infection crosses the border of stage 2 and enters stage 3 which is quite difficult to control because it affects the large community. In stage 3 one infected person spread infection to a community depending on the reproduction number of the disease. Its reproduction number is 3 then an infected person is communicable to 3 other healthy person. 
It finally stops at stage- 4 which is termed as epidemic stage with the heavy loss of life (Fig. 1). We must create awareness to prevent stage 3 to come. A small ignorance can lead to epidemic condition. Initially the concern was limited to China but very soon Italy has surpassed the cases of corona and condition soon became very critical. On 19 March 2020, 475 deaths have reported in Italy while China has never reported over 150 death. This is enough to explain the effect of epidemic nature of COVID-19. Till the end of March 2020 the condition has flipped the situation, the China has controlled its condition but became uncontrollable in USA and Italy. By the mid of April 2020, Spain, France, Germany, UK soon included in the list whereas Iran and Turkey are also on the way to exceed the condition of China. The condition of the cases in these countries are well defined by their reproduction number as mentioned in Table 1. Anavaibility of vaccine or defined treatment has suggested to take prevention than to wait for cure. The most effective method included in this series is social distancing. This has brought about lockdown in whole world.

\section{Evolution of COVID-19}

So far six types of coronavirus were already known and this came up as novel zoonotic disease which is transmitted to human from bat. Infection of four viruses- 229E, OC43, NL63, and HKU1 can be easily recovered by immunocompetent individuals [24]. However, SARS-CoV and MERS-CoV which break out in 2002/2003 and 2012 respective years develop severe acute respiratory syndrome which can be fatal [6]. SARS-CoV which was supposed to be transmitted to human from horseshoe bat and palm civets [14] has host-specific spike glycoprotein (S) which binds with the receptor angiotensin I. Binding of $S$ protein with the receptor causes its internalization through phagocytosis. During this process it gets cleaved by cathepsin $\mathrm{L}$ within the endosome spreading its infection and precedes fusion [22].

In the year 2002 and 2003 SARS-CoV became endemic in South China in Guangdong region [11]. Similarly, MERS-CoV, 2012 outbreak in middle east from bat [5] and dromedary camel [17]. With the evolution of time the mechanism of recombination in animals periodically bring about periodic cross-species infection. $\mathrm{CoV}$ is RNA based virus where recombination is more invited. In 2019, this recombination generated $2019-\mathrm{CoV}$ infection which has also transmitted from bat having $86.9 \%$ nucleotide sequence identity with SARS-like CoV [33] and very close to novel beta coronavirus of Coronaviridae family [25]. China was already suspected of such outbreak as Fan and their research group has shown the concern through his article in March 2019 [8]. Looking at the current concern this article aims to spread the general awareness and terminology associated with 2019- CoV.
Fig. 1 Different stages of transmission of COVID-19. Initially, it spread from one individual to other and from there to a community and at epidemic stage its spread from one community to others

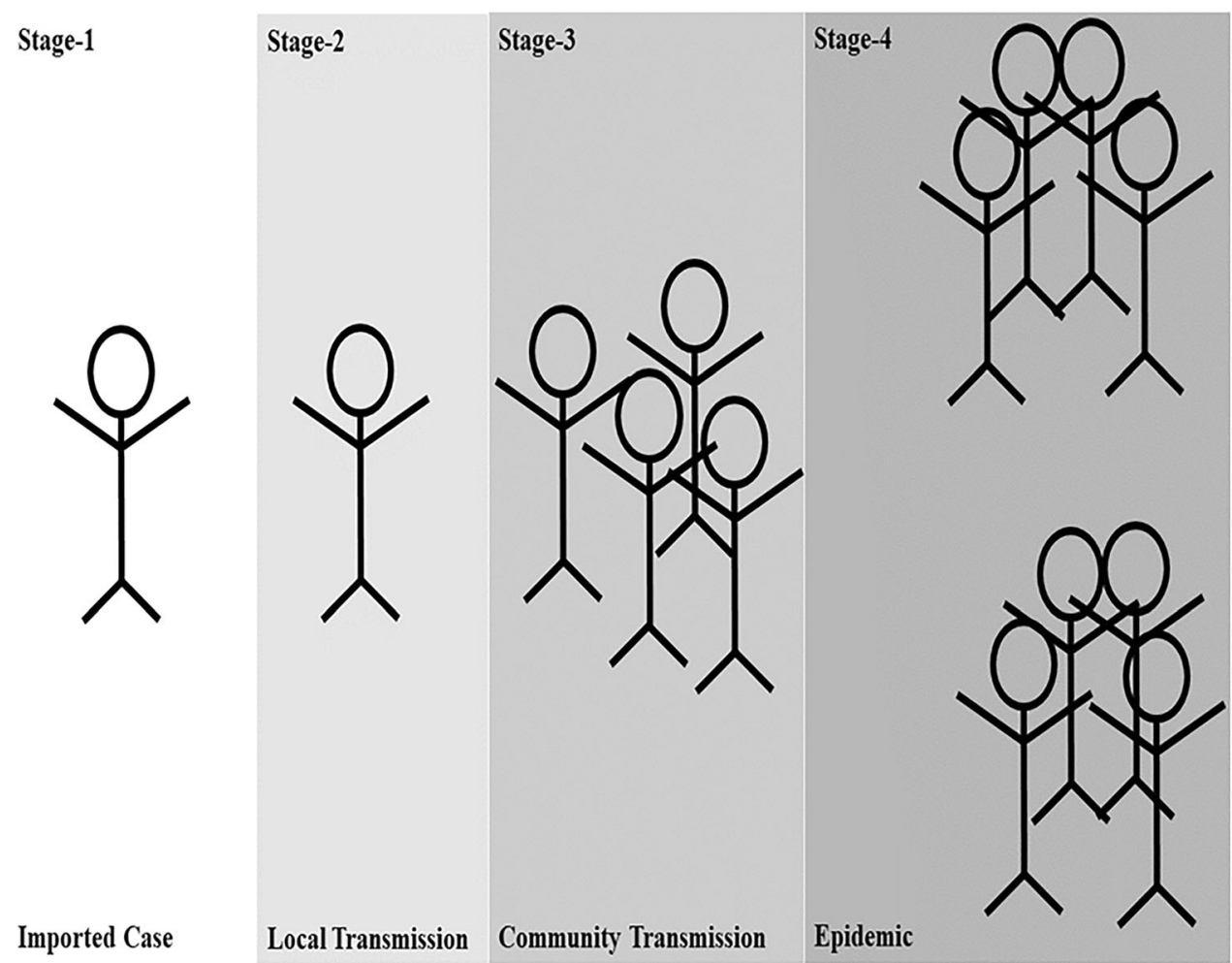


Table 1 Showing the number of cases, initial percentage of susceptible $\left(\mathrm{S}_{0}\right)$, attack rate (AR) and reproduction number $\left(\mathrm{R}_{0}\right)$ of different regions affected with 2019-CoV

\begin{tabular}{lrllllll}
\hline Country & Total population & Total cases & So $\%$ & Attack rate $\%$ & Ro & $1 /$ Ro & $(1-1 /$ Ro) \\
\hline USA & $1,43,93,23,776$ & $7,13,002$ & 0.051 & 0.2154 & 1.621 & 0.617 & 0.383 \\
Spain & $6,04,61,826$ & $1,91,726$ & 0.331 & 0.4101 & 0.970 & 1.031 & -0.031 \\
Italy & $33,10,02,651$ & $1,72,434$ & 0.053 & 0.2852 & 1.708 & 0.586 & 0.414 \\
France & $4,67,54,778$ & $1,47,969$ & 0.329 & 0.2267 & 0.835 & 1.198 & -0.198 \\
Germany & $8,37,83,942$ & $1,42,569$ & 0.178 & 0.1702 & 1.027 & 0.974 & 0.026 \\
UK & $8,39,92,949$ & $1,14,217$ & 0.145 & 0.1682 & 1.104 & 0.905 & 0.095 \\
China & $6,52,73,511$ & 82,719 & 0.127 & 0.0057 & 1.031 & 0.970 & 0.030 \\
Iran & $86,54,622$ & 80,868 & 0.992 & 0.0963 & 0.459 & 2.181 & -1.181 \\
Turkey & $5,12,69,185$ & 78,546 & 0.157 & 0.0931 & 1.016 & 0.984 & 0.016 \\
Belgium & $6,78,86,011$ & 37,183 & 0.058 & 0.3208 & 1.717 & 0.583 & 0.417 \\
Russia & $1,71,34,872$ & 36,793 & 0.243 & 0.0252 & 0.825 & 1.213 & -0.213 \\
Brazil & $90,06,398$ & 34,485 & 0.466 & 0.0162 & 0.627 & 1.595 & -0.595 \\
Canada & $1,15,89,623$ & 32,412 & 0.289 & 0.0859 & 0.800 & 1.250 & -0.250 \\
Netherlands & $54,21,241$ & 31,589 & 0.630 & 0.1844 & 0.604 & 1.655 & -0.655 \\
Switzerland & $1,01,96,709$ & 27,404 & 0.276 & 0.3166 & 0.966 & 1.035 & -0.035 \\
Portugal & $1,00,99,265$ & 19,685 & 0.204 & 0.1931 & 0.990 & 1.010 & -0.010 \\
India & $2,54,99,884$ & 14,792 & 0.060 & 0.0011 & 1.302 & 0.768 & 0.232 \\
Austria & $3,77,42,154$ & 14,671 & 0.040 & 0.1629 & 1.661 & 0.602 & 0.398 \\
Ireland & $21,25,59,417$ & 13,980 & 0.007 & 0.2831 & 2.856 & 0.350 & 0.650 \\
Sweden & $86,55,535$ & 13,822 & 0.180 & 0.1369 & 0.996 & 1.004 & -0.004 \\
Peru & $3,23,65,999$ & 13,489 & 0.042 & 0.0409 & 1.480 & 0.675 & 0.325 \\
Israel & $57,92,202$ & 13,107 & 0.231 & 0.1514 & 0.914 & 1.094 & -0.094 \\
S. Korea & $8,43,39,067$ & 10,653 & 0.013 & 0.0208 & 1.952 & 0.512 & 0.488 \\
\hline & & & & & & & \\
\hline
\end{tabular}

Reproduction Number

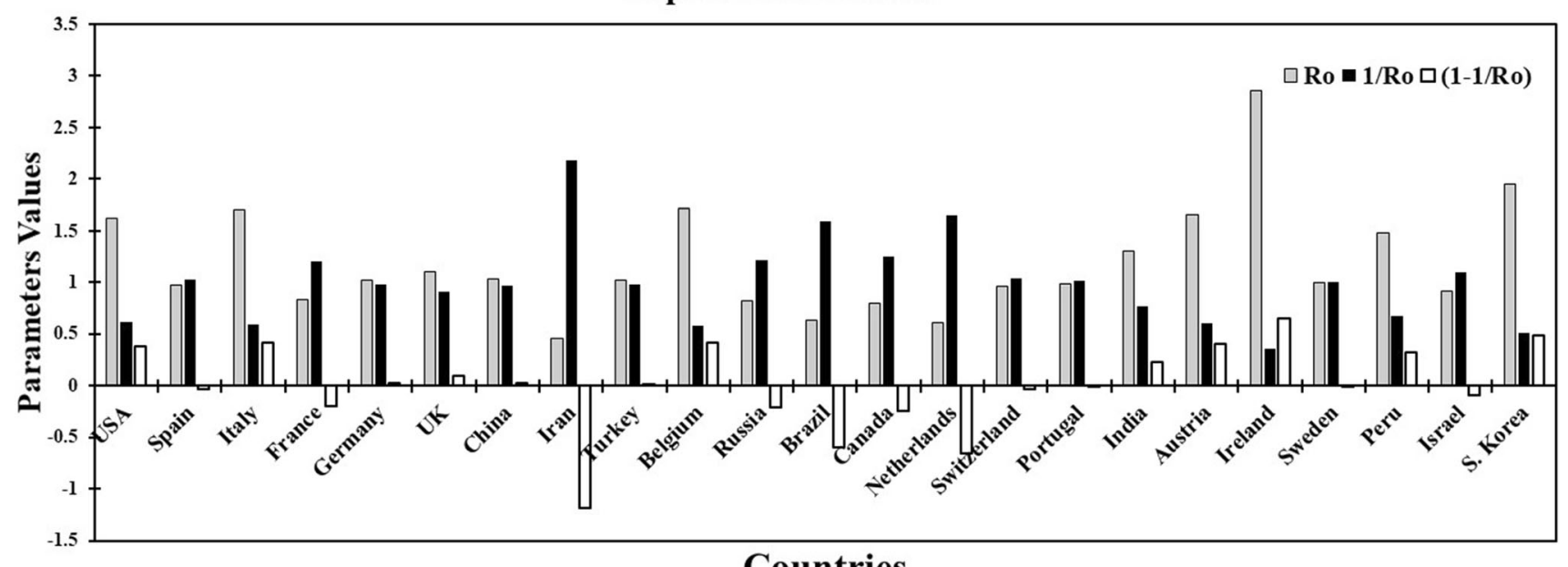

Countries

Fig. 2 Reproduction number of affected countries. Conversely, 1/Ro is the fraction of the population that remains susceptible to infection in the endemic equilibrium. $(1-1 / \mathrm{Ro})$ indicate the fraction of the

This new pandemic condition needs to know all the current scenario of the infection reflecting the reproduction number, symptoms, possible diagnosis, clinically tried treatment method and their success rate. This article will depict all the points with respect to public health and clinical demand. population that desires to be effectively vaccinated (meaning not susceptible to infection) to avoid sustained spread of the infection

\section{Search strategy}

This systematic review is based on the all authentic data and findings from WHO and associated research. Based on the current issue of corona infection the published data is analyzed with respect to the reproduction number of 
corona, symptoms shown by the patients admitted in the hospitals, diagnostic procedure and available clinical trial in vitro study. Reproductive number $\left(\mathrm{R}_{\mathrm{o}}\right)$ was calculated by using the formula $R_{o}=-\frac{\log \left(\frac{1-A R}{S o}\right)}{A R-(1-S o)}$. The formula uses the attack rate $(A R)$ i.e. the fraction of population ultimately infected. In the traditional SIR (Susceptible, Infected and Recovered) model of disease spread, the attack rate is associated to the basic reproduction number. The initial percentage of susceptible population is taken as $S_{0}$. The data used in the analysis are those countries which have more than 10,000 (2019-nCoV) as available in https:// www.worldometers.info/coronavirus/\#countries. This will help to get a clear picture of the $R_{o},\left(1-1 / R_{o}\right)$ and $1 / R_{o}$ values in further modelling process of the data.

\section{Reproduction number of covid 19}

Corona Infection which is now a day major concern worldwide need to root out. The analysis says that it is infecting with alarming rate as $\mathrm{R}_{\mathrm{o}}>1$ in most of the affected countries (Fig. 2). Which means the disease in epidemic is nature which is already proved. On 28 February 2020 globally there were 80,000 confirmed cases and till the end of March 2020 it has risen to more than 392,000 and death trolled to 17,146 as on 24 March and still increasing at the alarming rate. The cases have reached to 2,250,790 of which more than 154,000 has died and death rate has crossed 571,000 all over the world [28]. Though the lockdown across the world has lowered the $\mathrm{R}_{0}$ but this downfall is quite negligible. Still this sign is relaxing to hear.

The symptoms of COVID-19 are quite similar to SARS except running nose, sore throat and sneezing. Even its mechanism of infection is also similar to the corona infection busted in 2002 and 2012 [22] With this finding in vitro clinical trial using the same drugs which is used for SARS and MERS is in pace. Like the diagnostic process of SARS, RT-PCR is used on the basis of sequence submitted by WHO to online source virological.org on 10 January [31]. The infection which come from China has almost spreaded to all over the world. Though its effect is in control in China but cases are increasing rapidly in other countries including USA, Spain, Italy, France, Germany, and UK. But $\mathrm{R}_{0}$ in Spain and France is les than 1, 0.970 and 0.835 respectively. Italy has much effected of the death cases which may be due to the greater number of age person (median age 47.3) and still have $R_{0}>1$ (1.708) [29].

\section{The latent period of covid-19}

The latent period is the time between the exposure and outbreak of the symptoms. This is very crucial time as general awareness can prevent its infection to pass from one person to another. COVID-19 like sever acute respiratory syndrome (SARS) and $\mathrm{A} / \mathrm{H} 1 \mathrm{~N} 1$ influenza virus also has pre-intervention period having initial reproductive number of 2.2 in China [30]. It has minimum incubation period of 5 days similar to SARS and maximum of 14 days [15]. So, the social distancing for a certain period of time may decrease the rate of infection. As all the affected countries has implemented lockdown and this resulted in downfall of the reproduction number $\left(\mathrm{R}_{0}\right)$. At the end of March 2020 where the $R_{0}$ range from 1 to 3 has now decreased to 1 and even less. Ireland is only the exception where $\mathrm{R}_{0}>2$ (Table 1 ).

The Reproduction Number is used to determine the secondary transmition of disease in a population. Further, used to determine the proportion of population that should be immunized through vaccination to get rid of the infectious disease. In general, when $\mathrm{R}_{\mathrm{o}}>1$ the infection will jerk spreading in a population, else not, the larger the $R_{o}$, the tougher to control the epidemic. In simple models (work in progress), the value $\left(1-1 / \mathrm{R}_{\mathrm{o}}\right)$ indicate the fraction of the population that desires to be effectively vaccinated (meaning not susceptible to infection) to avoid sustained spread of the infection. Conversely, $1 / R_{o}$ is the fraction of the population that remains susceptible to infection in the endemic equilibrium (Table 1).

The basic reproduction number is affected by several factors including the duration of infectivity of affected patients, the infectiousness of the organism, and the number of susceptible people in the population that the affected patients are in contact with.

\section{Symptoms}

We all are surrounded by millions of microbes which are pathogenic. But our body resists most of these pathogens. Few bacterial and viral infection causes general symptoms of flu. Current situation of COVID-19 also starts with such symptoms which cause fear in general people even in normal flu. This article is trying to overcome this fear by depicting all the possible symptoms which need to consult doctor and follow the quarantine period as per the instruction from the health expert. The case erupted in China and when it comes in concern of medical expert, they found that after onset of infection body temperature raises term as fever in $98 \%$ cases at the median of 7 days. Next day (8th day) more than $50 \%$ of the infected person 
felt difficulty in breathing (Dyspnoea), on 9th day 29\% of the cases developed acute respiratory distress syndrome on 10th day $39 \%$ of the infected person was admitted to intensive care unit [13]. In rare of the cases headache, hemoptysis (Coughing up blood) and diarrhoea were also observed (Fig. 3).

\section{Diagnosis}

Reflection of symptoms of COVID-19 suggests undergoing diagnosis for the confirmation of infection. Next-generation sequencing or real-time RT-PCR is used to diagnose the presence of 2019-nCoV in the respiratory specimen. WHO has released a viral genome sequence for immediate public health in online source virological.org on 10 January (Wuhan-Hu-1, GenBank accession number MN908947) [31] further on 12 January four other genomes were deposited to Global Initiative on Sharing All Influenza Data (GISAID) which shows its similarity with SARS-related CoV. This data is quite helpful to design primers for PCR. The technique used forward primer 5'-ACTTCTTTTTCTTGCTTTCGTGGT-3'; reverse primer 5'-GCAGCAGTACGCACACAATC-3'; and the probe 5'CY5-CTAGTTACACTAGCCATCCTTAC TGC-3'BHQ1. The success of amplification using these sequences confirms the presence of infection. Alternative primer is also available which is listed in Table 2 [1].

Using RT-PCR, India based molecular diagnostic company 'Mylab' has designed a diagnostic kit which can diagnose 200 samples from small lab and 1000 samples from large labs in just $2.5 \mathrm{~h}$ [18].
Using this diagnostic method Zhou et al., have analyzed the survival rate of the virus in the affected person. The PCR result of throat swabs of affected persons who have survived shows that virus shaded in median of 20.0 days while the virus remained in the person who died of infection. The result is similar to the SARS and MERS [32].

\section{Treatment}

Researchers are continuously looking for the treatment of COVID-19, a new outbreak. Looking at its similarity with SARS and MERS, the drugs which proved effective against these syndromes were also tried on COVID-19 through in vitro study. Six nucleotide analogous drugs (ribavirin, nafamostat, penciclovir, nitazoxanide, flavipiravir and remdesivir) and one anti-malarial drug (chloroquine) were studied on Vero E6 cell against COVID-19. Each of these drugs was analysed for half-maximal effective concentration $\left(\mathrm{EC}_{50}\right)$, half cytotoxic concentration $\left(\mathrm{CC}_{50}\right)$, and selectivity index (SI) against the target virus (Table 3). It was observed that remdesivir is effect even at micromolar concentration with high SI. Remdesivir blocks the viral infection by early terminating the RNA transcription as in SARS/MERS-CoV [21]. As it targets the RNA it is functional at the stage of post-entry [27]. Promising result of remdesivir is also been reported in United States against COVID-19 [12] where initial dose of $200 \mathrm{mg}$ and then 100 $\mathrm{mg}$ for nine consecutive days was approved under trial in February 5, 2020 via intravenous infusion and expected to come up with promising result at the end of April 2020 [7].
Fig. 3 Clinical features shown by COVID-19 infection- X-axis represent the types of symptoms whereas Y-axis shows the percentage of individuals reflecting the said symptoms

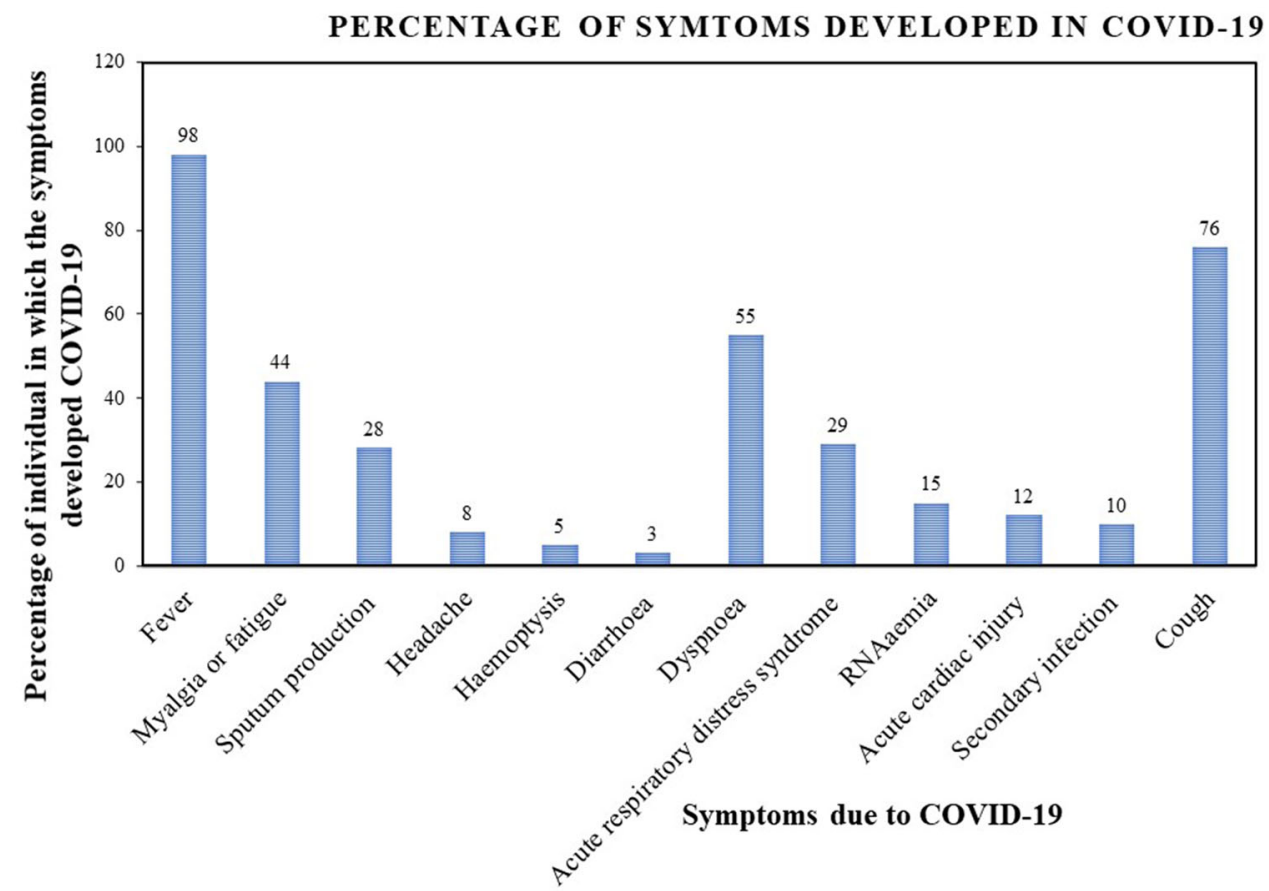


Table 2 Availability of primers for 2019-nCov

\begin{tabular}{llcl}
\hline Manufacturer & Product name & Catalog No. & Acceptable Lots \\
\hline $\begin{array}{l}\text { BioSearch Technologies www. } \\
\text { biosearchtech.com }\end{array}$ & $\begin{array}{c}\text { 2019-nCoV CDC Probe and Primer } \\
\text { Kit for SARS-CoV-2 }\end{array}$ & $\begin{array}{c}\text { KIT-nCoV- } \\
\text { PP1- 1000 }\end{array}$ & 143503 \\
$\begin{array}{l}\text { 1-800-GENOME-1 } \\
\begin{array}{l}\text { Integrated DNA Technologies } \\
\text { (IDT) www.idtdna.com }\end{array}\end{array}$ & 2019-nCoV Kit, 500 rxn & 10006606 & 000050038300005048470000505594 \\
(800) 328-2661 & & & 000050596900005072950000507509 \\
\hline
\end{tabular}

Table 3 In vitro response of different drugs against COVID-19 on Vero E6

\begin{tabular}{lllll}
\hline $\begin{array}{l}\text { S. } \\
\text { no. }\end{array}$ & Drugs & $\begin{array}{l}\text { Half-maximal effective concentration }\left(\mathrm{EC}_{50}\right) \\
(\mu \mathrm{M})\end{array}$ & $\begin{array}{l}\text { Half cytotoxic concentration }\left(\mathrm{CC}_{50}\right) \\
(\mu \mathrm{M})\end{array}$ & $\begin{array}{l}\text { Selectivity index } \\
(\mathrm{sI})\end{array}$ \\
\hline 1 & Ribavirin & 109.50 & $>400$ & $>3.65$ \\
2 & Penciclovir & 95.96 & $>400$ & $>4.17$ \\
3 & Nitazoxanide & 2.12 & $>35.53$ & $>16.76$ \\
4 & Nafamostat & 22.50 & $>100$ & $>4.44$ \\
$\mathbf{5}$ & Chloroquine & 1.13 & $>100$ & $>88.50$ \\
$\mathbf{6}$ & Remdesivir & 0.77 & $>100$ & $>129.87$ \\
7 & (GS5734) & & $>400$ & $>6.46$ \\
\hline
\end{tabular}

Infection with covid 19 causes inflammation in lungs which disconnect the hemoglobulin to carry required oxygen for the body. Chloroquine is the anti-inflammatory agent which even help to treat lupus erythematosus and rheumatoid arthritis at the effective dose of $500 \mathrm{mg}$ [16]. It has broad-spectrum antiviral activities which interferes with the glycosylation of cellular receptors by increasing endosomal $\mathrm{pH}$ a major requirement for the fusion of virus and cell [20]. The advantage of using chloroquine is that it is effective at both entries and at the post-entry stage of infection [21] and even act as immune modulator increases the potentiality as antiviral effect in vivo. It is bioavailable to whole body including lungs after administration. Presenting these findings in a conference on February 15, 2020 to the experts from government and regulatory authorities and organizers of clinical trials approved the use of chloroquine phosphate against COVID-19 [10].

Ribavirin is administered intravenously 2-3 times/day at a dose of $500 \mathrm{mg}$ to the adults in combination with IFN $\alpha$ or lopinavir/ritonavir. IFN- $\alpha$ is a broad-spectrum antiviral which is tested in vitro against SARS-CoV and proved effective in inhibiting its reproduction [23]. Lopinavir/ritonavir which is a medicine for the human immunodeficiency virus (HIV) is promising against SARS-CoV at in vitro trial [4].
Favipiravir was also approved on February 15, 2020, in China against COVID-19 after clinical trial by the Clinical Medical Research Centre of the National Infectious Diseases and the Third People's Hospital of Shenzhen on February 14. In its active form (phosphoribosylated), it pretends as a substate for RNA polymerase [9] causing suspension of viral growth [7]. Some Chinese herbs, Rhizoma Polygoni Cuspidati and Radix Sophorae Tonkinensis against SARS-CoV-2 are also under clinical trial.

In India to 3 out of 4 patients were treated in Jaipur at Sawai Man Sing Hospital by the combination of Lopinavir/ Ritonavir (used against HIV), chloroquine (anti-malarial) and oseltamivir drugs (treat swine flu) [26]. Now the researcher has moved to plasma therapy against critical condition and looking for the in vitro effect of leprosy drug. Plasma therapy is not a new attempt rather it has been used against many viral infections like hepatitis $B$, rabies and varicella zoster viruses. It was also proved effective against SARS [3]. Looking at the similarity index of COVID-19 with SARS many countries has approved the clinical trial of plasma therapy. In this process plasma is isolated from covid history patient with age $>18$ and transfused intravenously to Covid-19 patient. Though the result is still under analysis and even if it will be successful then it is difficult to meet the desired demand [19]. Though many steps have been taken and are in progress but yet not 
fully successful. So, it is better defined to prevent instead of waiting to be cured.

\section{Conclusion}

The time when corona has brought an international concern, this article aims to spread the knowledge of symptoms, preventive measure and possible treatment for COVID-19. Like SARs and MERS, it is also a zoonotic disease transmitted from bat to human at Wuhan, Hubei Province, China. It is named as 2019-nCoV. It is spreading at alarming rate to other countries. Condition of Italy is even more critical than China. On March 19 the death due to COVID-19 increased by $18.4 \%$ in Italy where previously it was $14.6 \%$. But other countries have also surpassed the number of cases. But the relaxing fact is that reproduction Number $\left(R_{0}\right)$ is decreasing which may be due to social distancing implanted in the form of lock down. This has definitely effected the economy but have positive impact on the environment.

This study has analysed all the possible symptoms with COVID-19. This will supress the fear if a person is suffering from common flu. All the possible clinical trial for treatment and their success rate is well presented in the paper which will help to formulate vaccine against COVID-19.

Acknowledgement We are thankful to Amity university Jharkhand for motivating us to initiate the write up for spreading the basic concern for COVID19. This work is not funded but this publication will assist us to drop project in future.

\section{Compliance with ethical standards}

Conflict of interest Authors do not have any conflict of interest.

\section{References}

1. CDC 2019-nCoV Real-Time RT-PCR Diagnostic Panel Acceptable Alternative Primer and Probe Sets April 10, 2020. https:// www.cdc.gov/coronavirus/2019-ncov/downloads/List-of-Accep table-Commercial-Primers-Probes.pdf.

2. Chen N, Zhou M, Dong X, et al. Epidemiological and clinical characteristics of 99 cases of 2019 novel coronavirus pneumonia in Wuhan, China: a descriptive study. Lancet. 2020;395:507-13. https://doi.org/10.1016/S0140-6736(20)30211-7.

3. Cheng Y, Wong R, Soo YO, Wong WS, Lee CK, Ng MH, Chan $\mathrm{P}$, Wong KC, Leung CB, Cheng G. Use of convalescent plasma therapy in SARS patients in Hong Kong. Eur J Clin Microbiol Infect Dis. 2005;24(1):44-6.

4. Chu CM, Cheng VCC, Hung IFN, et al. Role of lopinavir/ritonavir in the treatment of SARS: initial virological and clinical findings. Thorax. 2004;59:252-6.

5. Corman VM, Ithete NL, Richards LR, et al. Rooting the phylogenetic tree of middle East respiratory syndrome coronavirus by characterization of a conspecific virus from an African bat. J Virol. 2014;88:11297-303.

6. Cui J, Li F, Shi ZL. Origin and evolution of pathogenic coronaviruses. Nat Rev Microbiol. 2019;17:181-92.

7. Dong L, Hu S, Gao J. Discovering drugs to treat coronavirus disease 2019 (COVID-19). Drug Discover Therapeut. 2020;14(1):58-60.

8. Fan Y, Zhao K, Shi Z, et al. Bat Coronaviruses in China. Viruses. 2019;11:210. https://doi.org/10.3390/v11030210.

9. Furuta Y, Komeno T, Nakamura T. Favipiravir (T-705), a broad spectrum inhibitor of viral RNA polymerase. Proc Jpn Acad Ser B Phys Biol Sci. 2017;93:449-63.

10. Gao J, Tian Z, Yang X. Breakthrough: chloroquine phosphate has shown apparent efficacy in treatment of COVID-19 associated pneumonia in clinical studies. BioScience Trends. 2020;14(1):72-3.

11. Guan $\mathrm{Y}$, Zheng BJ, He YQ, et al. Isolation and characterization of viruses related to the SARS coronavirus from animals in southern China. Science. 2003;30:2276-8.

12. Holshue ML, DeBolt C, Lindquist S, et al. First case of 2019 novel coronavirus in the United States. $\mathrm{N}$ Engl J Med. 2020;382:929-36.

13. Huand $\mathrm{C}$, Wang $\mathrm{Y}, \mathrm{Li} \mathrm{X}$, et al. Clinical features of patients infected with 2019 novel coronavirus in Wuhan, China. The Lancet. 2020;395:497-506.

14. Lau SK, Woo PC, Li KS, et al. Severe acute respiratory syndrome coronavirus-like virus in Chinese horseshoe bats. Proc Natl Acad Sci USA. 2005;102:14040-5.

15. Lauer SA, Grantz KH, Bi Q, et al. The incubation period of coronavirus disease 2019 (COVID-19) from publicly reported confirmed cases: estimation and application. Ann Intern Med. 2020;1:1. https://doi.org/10.7326/M20-0504

16. Mackenzie AH. Dose refinements in long-term therapy of rheumatoid arthritis with antimalarials. Am J Med. 1983;75:40-5.

17. Paden CR, Yusof MFBM, Al Hammadi ZM, et al. Zoonotic origin and transmission of Middle East respiratory syndrome coronavirus in the UAE. Zoonoses Public Health. 2018;65:322-33.

18. Rajagopal D. The Economic Times. Pune based Mylab becomes first Indian company to get Covid-19 test kits validated. March 24, 2020. https://economictimes.indiatimes.com/industry/health care/biotech/healthcare/pune-based-mylab-becomes-first-indianco-to-get-its-covid-19-test-kits-validated/articleshow/74785575. $\mathrm{cms}$ ?from $=\mathrm{mdr}$.

19. Roback JD, Guarner J. Convalescent Plasma to Treat COVID-19: possibilities and Challenges. JAMA. 2020;1:1. https://doi.org/10. 1001/jama.2020.4940.

20. Savarino A, Boelaert JR, Cassone A, et al. Effects of chloroquine on viral infections: an old drug against today's diseases? Lancet Infect Dis. 2003;3:722727.

21. Sheahan TP, Sims AC, Graham RL, et al.Science Translational Medicine. Broad-spectrum antiviral GS-5734 inhibits both epidemic and zoonotic coronaviruses. Sci Transl Med. 2017;9:eaal3653.

22. Simmons G, Gosalia DN, Rennekamp AJ, et al. Inhibitors of cathepsin L prevent severe acute respiratory syndrome coronavirus entry. Proc Natl Acad Sci USA. 2005;102:11876-81.

23. Stockman LJ, Bellamy R, Garner P. SARS: systematic review of treatment effects. PLoS Med. 2006;3:e343.

24. Su S, Wong G, Shi W, et al. Epidemiology, genetic recombination, and pathogenesis of coronaviruses. Trends Microbiol. 2016;24:490-502.

25. Tan WJ, Zhao X, Ma XJ, et al. A novel coronavirus genome identified in a cluster of pneumonia cases-Wuhan, China 2019 - 2020. China CDC Weekly. 2020;2:61-2. 
26. The Times of India. Rajasthan: Jhunjhunu coronavirus patients shifted to Sawai Man Singh Hospital. March 20, 2020. https:// timesofindia.indiatimes.com/city/jaipur/jhunjhunu-patients-shif ted-to-sms/articleshow/74720541.cms.

27. Wang M, Cao R, Zhang L, et al. Remdesivir and chloroquine effectively inhibit the recently emerged novel coronavirus (2019nCoV) in vitro. Cell Res. 2020;30:269-71.

28. World Health Organization. Coronavirus disease 2019 (COVID19): Situation Report-38. 27 February 2020. www.who.int/docs/ default-source/coronaviruse/situation-reports/20200227-sitrep38-covid-19.pdf?sfvrsn=9f98940c_2.

29. Worldometer, Italy demography (2020). https://www.world ometers.info/world-population/italy-population/.

30. Wu P, Hao X, Lau EH, et al. Real-time tentative assessment of the epidemiological characteristics of novel coronavirus infections in Wuhan, China, as at 22 January 2020. Euro Surveill. 2020;25:2000044.

31. Zhang YZ. Novel 2019 coronavirus genome. Virological. 2020. http://virological.org/t/novel-2019-coronavirus-genome/319.

32. Zhou F, Yu T, Du R, et al. Clinical course and risk factors for mortality of adult inpatients with COVID-19 in Wuhan, China: a retrospective cohort study. Lancet 2020. published online March 9. https://doi.org/10.1016/S0140-6736(20)30566-3.

33. Zhu N, Zhang D, Wang W, et al. A novel coronavirus from patients with pneumonia in China, 2019. N Engl J Med. 2020;382:727-33. https://doi.org/10.1056/NEJMoa2001017.

Publisher's Note Springer Nature remains neutral with regard to jurisdictional claims in published maps and institutional affiliations. 